CONF-950412--19

Note: This is a preprint of a paper being submitted for publication. Contents of this paper should not be quoted nor referred to without permission of the author(s).

To be presented in Symposium $Q$

"Film Synthesis and Growth Using Energetic Beams" of the 1995 Spring Meeting of The Materials Research Society

\title{
Growth of Highly Doped p-Type ZnTe Films by Pulsed Laser Ablation in Molecular Nitrogen
}

Douglas H. Lowndes, ${ }^{*}$ C. M. Rouleau, ${ }^{* \dagger}$ J. W. McCamy, ${ }^{* *}$ J. D. Budai, ${ }^{*}$ D. B. Poker, ${ }^{*}$ D. B. Geohegan, ${ }^{*}$ A. Puretzky, ${ }^{* * *}$ and Shen $\mathrm{Zhu}^{* \#}$

* Solid State Division, Oak Ridge National Laboratory, P. O. Box 2008, Oak Ridge, TN 37831-6056

* Division of Applied Science, Harvard University, Cambridge, MA 02138

*** Institute of Spectroscopy, Troitsk, Russia

† ORISE postdoctoral researcher

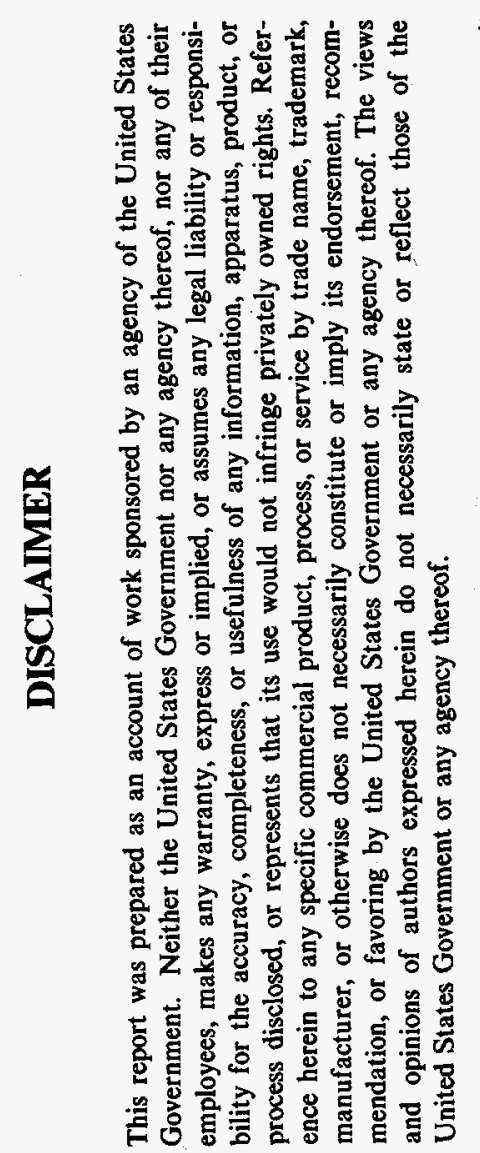

\# Now at Dept. of Physics, U. of Missouri, Columbia, MO 65211

Solid State Division

Oak Ridge National Laboratory

P. O. Box 2008

Oak Ridge, Tennessee 37831-6056

managed by

MARTIN MARIETTA ENERGY SYSTEMS, INC.

for the

U.S. DEPARTMENT OF ENERGY

under contract DE-AC05-84OR21400

April 1995

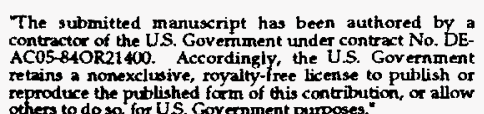




\section{DISCLAIMER}

Portions of this document may be illegible in electronic image products. Images are produced from the best available original document. 


\title{
GROWTH OF HIGHLY DOPED p-TYPE ZnTe
} PULSED LASER ABLATION IN MOLECULAR NITROGEN

\author{
DOUGLAS H. LOWNDES, ${ }^{*}$ C. M. ROULEAU, ${ }^{*} \dagger$ J. W. McCAMY,** J. D. BUDAI,* D. B. \\ POKER,* D. B. GEOHEGAN,* A. PURETZKY,*** and SHEN ZHU*\# \\ * Solid State Division, Oak Ridge National Laboratory, \\ P. O. Box 2008, Oak Ridge, Tennessee 37831-6056 \\ ** Division of Applied Science, Harvard University, Cambridge, MA 02138 \\ *** Institute of Spectroscopy, Troitsk, Russia \\ $\dagger$ ORISE postdoctoral researcher \\ \# Now at Dept. of Physics, U. of Missouri, Columbia, MO 65211
}

\section{ABSTRACT}

Highly p-doped $\mathrm{ZnTe}$ films have been grown on semi-insulating GaAs (001) substrates by pulsed-laser ablation (PLA) of a stoichiometric ZnTe target in a high-purity $\mathrm{N}_{2}$ ambient without the use of any assisting (DC or AC) plasma source. Free hole concentrations in the mid-10 $10^{19} \mathrm{~cm}^{-3}$ to $>10^{20} \mathrm{~cm}^{-3}$ range were obtained for a range of nitrogen pressures The maximum hole concentration equals the highest hole doping reported to date for any wide band gap II-VI compound. The highest hole mobilities were attained for nitrogen pressures of 50-100 mTorr ( $6.5-13 \mathrm{~Pa})$. Unlike recent experiments in which atomic nitrogen beams, extracted from RF and DC plasma sources, were used to produce p-type doping during molecular beam epitaxy deposition, spectroscopic measurements carried out during PLA of $\mathrm{ZnTe}$ in $\mathrm{N}_{2}$ do not reveal the presence of atomic nitrogen. This suggests that the high hole concentrations in laser ablated $\mathrm{ZnTe}$ are produced by a new and different mechanism, possibly energetic beam-induced reactions with excited molecular nitrogen adsorbed on the growing film surface, or transient formation of $\mathbf{Z n}-\mathbf{N}$ complexes in the energetic ablation plume. This appears to be the first time that any wide band gap $\left(E_{g}>2 \mathrm{eV}\right.$ ) II-VI compound (or other) semiconductor has been impurity-doped from the gas phase by laser ablation. In combination with the recent discovery that epitaxial $\mathrm{ZnSe}_{1-x} \mathrm{~S}_{x}$ films and heterostructures with continuously variable composition can be grown by ablation from a single target of fixed composition, these results appear to open the way to explore PLA growth and doping of compound semiconductors as a possible alternative to molecular beam epitaxy.

\section{INTRODUCTION}

Wide band gap II-VI semiconductors are recognized as prime candidate materials for blue lightemitting diodes (LEDs) and diode lasers. However, all wide band gap II-VI semiconductors exhibit a pronounced preference for only one type of doping (e.g., $\mathrm{ZnSe}$ is normally $n$-type and ZnTe $p$-type) due to self-compensation. Consequently, heteroepitaxial growth seemed to be required for $p-n$ junction formation, making necessary careful lattice matching of dissimilar ternary or quaternary materials to avoid strain and rapid degradation of diode performance at high current levels. Recently however, $p$-type doping of $\mathrm{ZnSe}$ was achieved by a nonequilibrium method, using MBE growth and a nitrogen RF plasma source, 1,2 and resulted in fabrication of the first blue-green LEDs and diode lasers. ${ }^{3,4}$ Formation of ohmic contacts to $\mathrm{p}-\mathrm{ZnSe}$ remained a problem because the hole concentration was limited to $\sim 10^{18} \mathrm{~cm}^{-3}$. A partial solution was found when a similar nitrogen RF plasma source was used to grow $\mathrm{p}-\mathrm{ZnTe}$ layers ${ }^{5}$ with hole concentrations $\sim 10^{19} \mathrm{~cm}^{-3}$ and a graded $\mathrm{p}-\mathrm{ZnTe} \mathrm{e}_{-x} \mathrm{Se}_{x}$ layer was used to contact $\mathrm{ZnSe}{ }^{6}$ Infrared spectroscopic measurements were used to verify that the species responsible for efficient $p$-doping using RF plasma sources is almost certainly atomic nitrogen. ${ }^{7}$ Most recently, two groups have shown that still higher hole concentrations, approaching $10^{20} \mathrm{~cm}^{-3}$, can be obtained for ZnTe by using a DC nitrogen plasma and MBE growth.,9 The DC plasma source is said to be cheaper and simpler to operate than the RF source. 8

In this paper we report the growth of highly doped p-type $\mathrm{ZnTe}$ films on semi-insulating GaAs (001) substrates by PLA of a stoichiometric $\mathrm{ZnTe}$ target through a high purity $\mathrm{N}_{2}$ ambient without the use of any assisting ( $D C$ or $A C$ ) plasma source. The maximum hole concentration equals the

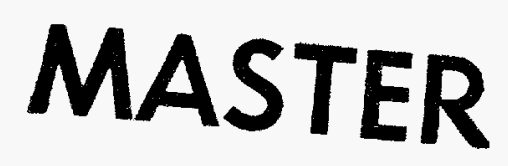


highest obtained for ZnTe by any method thus far. ${ }^{8}$ PLA differs from many other film growth methods in that growth occurs from a highly nonequilibrium pulsed flux of energetic atoms, ions, and electrons. Spectroscopic measurements carried out during PLA of $\mathrm{ZnTe}$ in $\mathrm{N}_{2}$ do not reveal the presence of atomic nitrogen. This suggests that the high hole concentrations in PLA ZnTe are produced by a new and different mechanism, possibly energetic beam-induced reactions with excited molecular nitrogen adsorbed on the growing film surface, or transient formation of $\mathrm{Zn}-\mathrm{N}$ complexes in the energetic ablation plume.

All but one of the few previous attempts to deliberately dope laser ablated II-VI films involved substitutions on the column-II site, using ablation targets that were pressed-powder mixtures containing the dopant atom. Shen and Kwok grew (001)-oriented zinc blend CdS films $\left(E_{g}=2.50\right.$ $\mathrm{eV}$ ) on (001) GaAs and InP substrates by adding Li3 $\mathrm{N}$ or In powders, respectively, to $\mathrm{CdS}$ targets, and obtained electron and hole concentrations in the $10^{19}-10^{20} \mathrm{~cm}^{-3}$ and $\sim 10^{17} \mathrm{~cm}^{-3}$ ranges, respectively. 10 Similarly, Compaan and co-workers ${ }^{11,12}$ grew polycrystalline p-ZnTe films on glass substrates by mixing metallic $\mathrm{Cu}$ and ZnTe powders in a pressed target. A hole concentration in the $10^{18}-10^{19} \mathrm{~cm}^{-3}$ range was estimated. However, both of these efforts required dopant-atom concentrations in the targets that far exceeded the resulting carrier concentrations, indicating that most dopant atoms either were not incorporated or were electrically inactive. Dubowski and co-workers grew epitaxial CdTe $\left(E_{\mathrm{g}}=1.49 \mathrm{eV}\right)$ and $\mathrm{Cd}_{1-x} \mathrm{Mn}_{x} \mathrm{Te}$ films by PLA, as well as dilute magnetic semiconductor superlattice and quantum well structures. ${ }^{13-16}$ However, no doping of either material was achieved. 17 Nevertheless, their results are encouraging in demonstrating PLA-grown heterostructures comparable in structural quality to those grown by MBE. $13,14,18$

\section{EXPERIMENTAL}

A conventional PLA system was used together with a pulsed $\mathrm{KrF}(248 \mathrm{~nm})$ excimer laser. 19 Cylindrical lenses brought the laser beam to a horizontal line focus ( $-9 \mathrm{~mm} \times \sim 0.75 \mathrm{~mm})$ at an energy density $\mathrm{E}_{\mathrm{d}} \sim 0.66 \mathrm{~J} / \mathrm{cm}^{2}$ along the radius of a $25.4 \mathrm{~mm}$-diam ZnTe target. 20 The target was rotated at $\sim 8 \mathrm{rpm}$ and the laser beam was switched alternately from one side of the target to the other to prevent cones from forming, thereby maintaining a smooth target surface and a uniform deposition rate. 19 This resulted in ZnTe films that were free of particulates. ${ }^{21}$ The ultra-high purity (six nines) $\mathrm{N}_{2}$ dopant gas was introduced through a mass-flow controller (MFC). In some experiments Ar gas, controlled by a second MFC, was introduced to permit variation of the ablation beam's kinetic energy (via collisions with ambient gas molecules) independent of the $\mathrm{N}_{2}$ dopant-gas partial pressure. The total chamber pressure was controlled by a capacitance manometer and a throttle valve. Single-crystal semi-insulating (001) GaAs substrates were solvent-cleaned and sulfur-passivated as described elsewhere. 22 The substrate heater face was located $10 \mathrm{~cm}$ from the ZnTe target because in situ ion probe measurements had indicated that at this separation the ablation beam's kinetic energy could be reduced by collisions into the range expected to assist epitaxial film growth, while still using $\mathrm{N}_{2}$ pressures $(\sim 50-100 \mathrm{mTorr})$ that seemed likely to produce doping. 22,23 No external power supplies or biasing arrangements were used, only the pulsed laser-generated plasma inherent to the ablation process.

The substrate heater was rotated at $\sim 9 \mathrm{rpm}$ which, combined with the ablation beam-switching, produced films with reasonably uniform thickness. The film-growth rate was monitored in situ using a reflectance interferometer consisting of a low-power $\mathrm{HeNe}$ laser and large-area $\mathrm{Si}$ photodiode. The $\mathrm{ZnTe}$ films were grown to a nominal thickness of $676 \mathrm{~nm}(1 \mu \mathrm{m}$ in initial experiments) in order to minimize effects of the dense dislocation network propagating from the $\mathrm{ZnTe}-\mathrm{GaAs}$ interface 24 and make possible meaningful intercomparisons of Hall effect measurements of hole concentration and mobility. ${ }^{8}$ All of the results reported here were obtained at a growth temperature of $320^{\circ} \mathrm{C}$ and an average $\mathrm{ZnTe}$ growth rate of $1 \AA / \mathrm{sec}$, corresponding to laser pulse repetition rates of $\sim 2.5$ to $\sim 4.5 \mathrm{~Hz}$, depending on the ambient gas pressure.

\section{FILM STOICHIOMETRY, ELECTRICAL, AND STRUCTURAL PROPERTIES}

Achievement of the ideal 1:1 stoichiometry ratio is crucial to control the electrical properties of II-VI (and other) compound semiconductors. Relatively small concentrations of vacancies on either sublattice can act as electrically active defects or can form complexes with deliberately 
introduced dopant atoms, producing compensation. Figure 1 shows results of Rutherford Backscattering Spectrometry (RBS) measurements of the $\mathrm{Zn} / \mathrm{Te}$ ratio in $~ 104-\mathrm{nm}$ thick $\mathrm{ZnTe}$ films that were deposited on Si substrates in vacuum and in $100 \mathrm{mTorr} \mathrm{N}_{2}$ at $E_{d}-0.66 \mathrm{~J} / \mathrm{cm}^{2}$. (A Si substrate was used for RBS measurements rather than GaAs to avoid interferences from the $\mathrm{Ga}$ or As RBS peaks.) The horizontal lines at $1.00 \pm 0.015$ represent the bounds of expected results for a series of RBS measurements on a ZnTe film with the ideal 1:1 stoichiometry. The ZnTe film deposited in $100 \mathrm{mT} \mathrm{N}_{2}$ is stoichiometric over much of its surface, while the film deposited in vacuum is $\mathrm{Zn}$-deficient by a statistically significant amount near the center of the (rotating) substrate heater face. The result that the PLA ZnTe film deposited in $100 \mathrm{mT} \mathrm{N} 2$ is stoichiometric, at least to within the accuracy of RBS, is remarkable because recent MBE growth of $\mathrm{ZnTe}$ required $\mathrm{Te} / \mathrm{Zn}$ flux ratios of 4 to 8 to achieve the highest hole concentration $\left(-7 \times 10^{19} \mathrm{~cm}^{-3}\right)$ and high hole mobility $\left(\sim 25-30 \mathrm{~cm}^{2} / \mathrm{V}-\mathrm{s}\right)$ in films $\sim 1 \mu \mathrm{m}$ thick. ${ }^{8}$ The combination of RBS and Hall measurements presented here strongly suggests that ZnTe films with nearly the ideal 1:1 stoichiometry can be grown by PLA of a stoichiometric ZnTe target.

Hall effect measurements were used to determine the free hole concentration, p, and mobility, $\mu_{\mathrm{p}}$, at room temperature and in liquid nitrogen $(\mathrm{T}=77 \mathrm{~K})$. As shown in Table $\mathrm{I}$ and Fig. 2, a maximum hole concentration $>1.1 \times 10^{20} \mathrm{~cm}^{-3}$ has been obtained to date, but high hole concentrations, in the mid- $10^{19} \mathrm{~cm}^{-3}$ range, were obtained for a range of nitrogen pressures, $\mathrm{p}\left[\mathrm{N}_{2}\right]$, and growth conditions. Figure 2 shows measurements of $\mathrm{p}$ and $\mu_{\mathrm{p}}$ for a series of $\mathrm{ZnTe}$ films grown at different $\mathrm{p}\left[\mathrm{N}_{2}\right]$ values. All other growth conditions and the final film thickness were held constant. The hole concentration is nearly constant at $2-3 \times 10^{19} \mathrm{~cm}^{-3}$ for $50 \mathrm{mT}<\mathrm{p}\left[\mathrm{N}_{2}\right]<200 \mathrm{mT}$, but falls to $\sim 2 \times 10^{18} \mathrm{~cm}^{-3}$ at $\mathrm{p}\left[\mathrm{N}_{2}\right]=25 \mathrm{mT}$. The hole concentrations are essentially the same at room temperature and $77 \mathrm{~K}$, indicating heavy doping and the formation of an impurity conduction band. ZnTe films grown in pure argon were electrically insulating, while ZnTe films grown in a $25: 75 \mathrm{~N}_{2}$ : Ar mixture at $100 \mathrm{mT}$ Torr total pressure (using $E_{d}=2.7 \mathrm{~J} / \mathrm{cm}^{2}$ ) had hole concentrations of $0.7-1.5 \times 10^{19} \mathrm{~cm}^{-3}$, consistent with doping that is controlled by the presence of nitrogen.

Figure 2 shows that the hole mobility peaks sharply at $\mathrm{p}\left[\mathrm{N}_{2}\right]=50 \mathrm{mT}$. We attribute this peak, and the less pronounced maximum in the hole concentration, primarily to effects of the ablation beam's kinetic energy, at low $\mathrm{p}\left[\mathrm{N}_{2}\right]$, and possibly to excessive $\mathrm{N}$ incorporation and accompanying lattice strain, at high $\mathrm{p}\left[\mathrm{N}_{2}\right]$ (see below). At low $\mathrm{p}\left[\mathrm{N}_{2}\right]$, including vacuum, there is evidence that the kinetic energy of ablated atoms and ions may be sufficient to damage the growing film's crystalline structure, for example by displacing host and nitrogen atoms from substitutional sites and thereby introducing point defects (vacancies and interstitials) that scatter mobile carriers, reducing both the hole mobility and the hole concentration (via compensation). Geohegan et al. have used ion probe measurements to show that for ablation into an ambient gas, the ablation plume quite generally splits into two or more distinct components traveling at different average velocities. 25 They interpret the fastest pulse as consisting of ions that have undergone no collisions with gas molecules before arriving at the substrate. Although this "fast pulse" is exponentially attenuated by increasing the ambient gas pressure or the target-substrate separation, it remains significant for $\mathrm{ZnTe}$ ablation into $\mathrm{N}_{2}$ until the $\mathrm{N}_{2}$ pressure is increased to $-50 \mathrm{mTorr}$, consistent with the occurrence of the hole mobility peak in Fig. 2. A second factor that may affect the hole mobility at high $\mathrm{p}\left[\mathrm{N}_{2}\right]$ values is that the kinetic energy of incident species may actually assist processes of surface diffusion, substitutional incorporation, and/or activation of $\mathrm{N}$ atoms on Te sites at moderate pressures, but this energy is reduced by numerous gas-phase collisions at high $\mathrm{p}\left[\mathrm{N}_{2}\right]$. These ideas regarding the effects of ablation-beam kinetic energy on the electrical properties of $\mathrm{ZnTe}$ films are being evaluated with the help of in situ time-resolved ICCD-camera and ion probe measurements. 23,25

Table I summarizes the results of high resolution $\mathrm{X}$-ray diffraction (HRXRD) measurements that were performed on $\mathrm{ZnTe}$ films grown under various conditions. The film with the highest hole concentration and mobility was fully epitaxial in three dimensions in the "cube on cube" (001) orientation, with no other $\mathrm{ZnTe}$ orientations present and with the film and substrate $<00 \mathrm{l}>$ axes precisely aligned. This orientation was also dominant in films grown in Ar or $\mathrm{N}_{2}$ ambients at much higher $E_{d}$, but very small amounts $(<1 \%)$ of the $\mathrm{ZnTe}(311)$ and $(111)$ orientations were present under these conditions. In-plane epitaxy was studied via $\varnothing$-scans with the other diffractometer angles set for the $\mathrm{ZnTe}(404)$ reflection; these revealed sharp peaks every $90^{\circ}$ in all 
cases, as expected for a single dominant orientation (see inset, Fig. 3). Most interestingly, for the film with the highest hole concentration and mobility the surface-normal and in-plane lattice parameters were $6.0755( \pm 0.002) \AA$ and $6.078 \AA$, respectively, nearly identical but both $\sim 0.4 \%$ smaller than the bulk ZnTe value of $6.100 \AA$. A reduced in-plane lattice parameter was also found for another film grown in nitrogen, but not for a film grown in argon (see Table I). These results strongly suggest that substantial nitrogen incorporation on substitutional sites is responsible for the lattice contraction in PLA ZnTe:N films, consistent with their highly p-type conductivity. The decreased hole mobility at high p $\left.\mathrm{N}_{2}\right]$ (Fig. 2) may be due to the lattice distortion that accompanies very high $\mathrm{N}$ concentrations in the solid phase (Table I). Rocking curve ( $\theta$-scan) measurements through the $\mathrm{ZnTe}(004)$ reflection revealed a significant apparent mosaic spread in all the films (see Table I), but with the greatest line broadening for the $\mathrm{N}$-doped samples, again consistent with heavy doping. (Possible additional effects of different laser $E_{d}$ values on $\Delta \theta(004)$ are also apparent in Table I.) Fig. 3 shows that most of the width of the $\mathrm{ZnTe}(00 \mathrm{l})$ diffraction peaks is due to strain. From the intercepts in the plot of $\Delta \mathrm{Q}$ vs. $\mathrm{Q}$, coherence lengths, $\Delta \mathrm{L} \sim 5.6 / \Delta \mathrm{Q}$, of $\sim 110-190 \mathrm{~nm}$ are obtained.

Table I. HRXRD results and electrical properties for $\mathrm{ZnTe}$ films grown in nitrogen and argon.

\begin{tabular}{|c|c|c|c|c|c|c|c|}
\hline Ambient & $\underset{\left(\mathrm{J} / \mathrm{cm}^{2}\right)}{\underline{E}_{\mathrm{d}}}$ & $\frac{\text { Thickness }}{(\mathrm{nm})}$ & $\frac{\text { Hole conc. }}{\left(10^{20} \mathrm{~cm}^{-3}\right)}$ & $\frac{\text { Mobility }}{\left(\mathrm{cm}^{2} / \mathrm{V}-\mathrm{s}\right)}$ & $\frac{\underline{\mathrm{a}} \perp}{(\AA)}$ & $\begin{array}{l}\text { âf } \\
(\AA)\end{array}$ & $\frac{\Delta \theta(004)}{(\mathrm{deg})}$ \\
\hline $\mathrm{T} \mathrm{N}_{2}$ & 0.66 & 676 & $1.18(1.1)$ & $15.8(22.1)$ & 6.075 & 6.078 & 1.06 \\
\hline 100 & 2.7 & $\sim 1000$ & $0.3 \quad(0.6)$ & $5.5(2.6)$ & 6.102 & 6.094 & 1.1 \\
\hline $50 \mathrm{~m}$ & 2.7 & $\sim 1000$ & --- & --- & 6.100 & 6.100 & 0.47 \\
\hline
\end{tabular}

Notes: $a_{\perp}$ and a\|l are the lattice constants $( \pm 0.002 \AA)$ perpendicular and parallel to the film. $\Delta \theta(004)$ is the rocking curve FWHM. Hole concentrations and mobilities are measured at room temperature $(77 \mathrm{~K})$. The gas flow conditions differ from the data shown in Fig. $1 .^{26}$

\section{IN SITU SPECTROSCOPY AND DOPING MECHANISM}

The interaction of the energetic laser-generated plasma "plume" with molecular $\mathrm{N}_{2}$ was studied in a chamber equipped with a gated ( $\geq 5-n s)$, intensified-CCD, lens-coupled camera system (200-820 nm response) for time-resolved imaging, and an ion probe for ion/electron current measurements. 23 Optical emission was monitored using a 1.33 -m monochromator equipped with an 1800 groove/mm holographic grating, a gated intensified diode array, and a photomultiplier tube.

The principal result of spectroscopic measurements at a distance of $7 \mathrm{~cm}$ from the $\mathrm{ZnTe}$ target during PLA in molecular $\mathrm{N}_{2}$ was that no emission was observed from either excited atomic nitrogen or excited molecular nitrogen. On the other hand, when a nitrogen glow discharge was established between parallel $\mathrm{Cu}$ plates in the same chamber, strong near-infrared $\mathrm{N}^{+}$atomic emission lines and an $\mathrm{N}_{2}{ }^{+}$emission band were seen.

The lack of atomic $\mathrm{N}$ emission from the PLA plasma in our experiments contrasts with the recent observation by Vaudo et al. ${ }^{7}$ of strong near-IR atomic $\mathrm{N}$ lines emitted from the nitrogen plasma produced by an RF source that is used for N-doping in MBE growth. They concluded that $\mathrm{N}$ atoms, rather than $\mathrm{N}_{2}$ molecules, are the species most likely responsible for p-type doping of $\mathrm{ZnSe}$ (and $\mathrm{ZnTe}$ ) under MBE growth conditions. ${ }^{7}$ Although our experiments do not directly rule out the presence of atomic $N$ in the ground state during PLA, this seems very unlikely because the dissociation energy of $\mathrm{N}_{2}$ is nearly $10 \mathrm{eV}$; if atomic $\mathrm{N}$ were produced by dissociation of $\mathrm{N}_{2}$ during PLA then we would expect also to see emission from excited $\mathrm{N}_{2}$, which we did not. Vaudo et al. observed also that the relative intensities of the near-IR atomic $\mathrm{N}$ and molecular $\mathrm{N}_{2}$ emissions depend sensitively on MBE chamber pressure, with the atomic $\mathrm{N}$ emission nearly disappearing as the pressure was raised from $2 \times 10^{-6}$ Torr to $5 \times 10^{-5}$ Torr. ${ }^{7}$ This suggests that even if atomic $\mathrm{N}$ were produced in the ablation plume at the higher pressures used here, it would be short-lived due to the increased probability of collisions and rapid recombination, so is unlikely to be involved in doping at the substrate. 

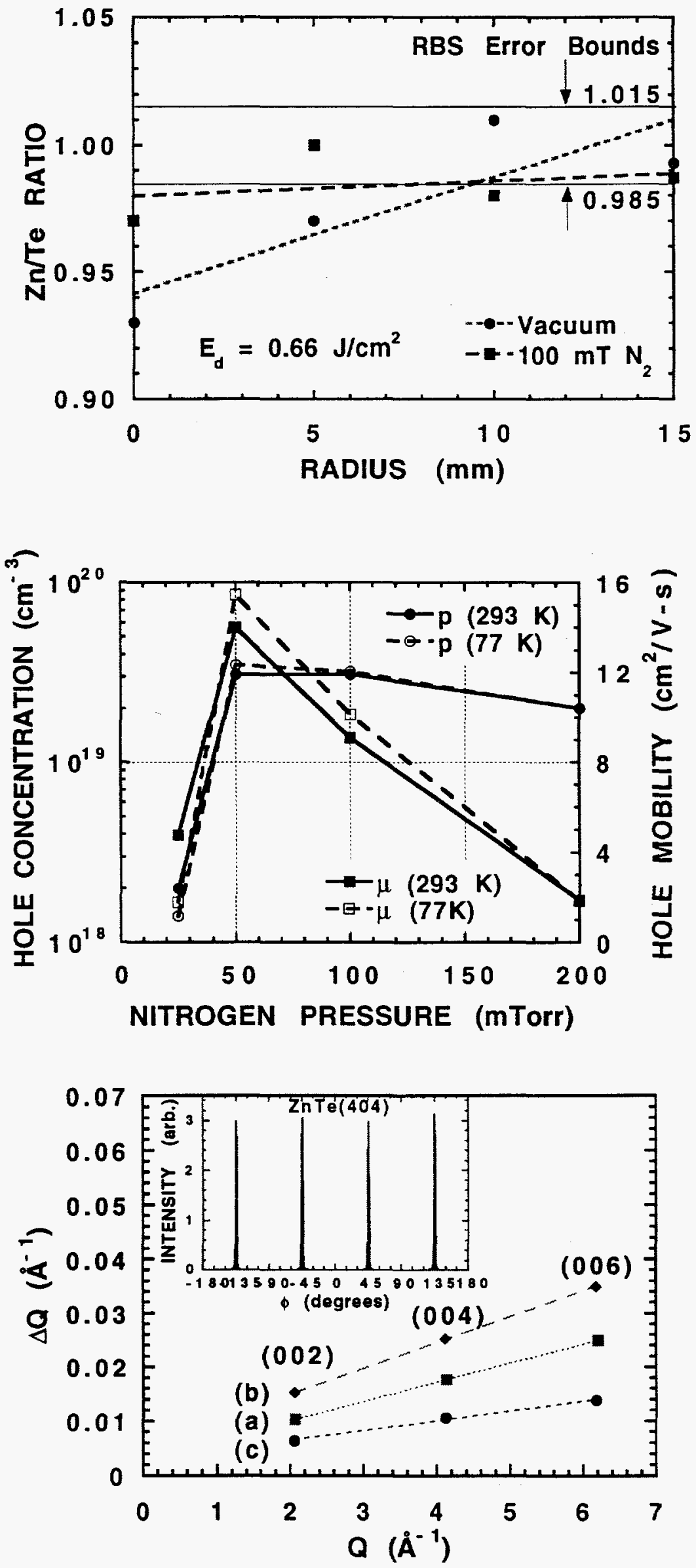

Figure 1. RBS measurements of the $\mathrm{Zn} / \mathrm{Te}$ ratio in $\mathrm{ZnTe}$ films deposited in vacuum and in 100 $\mathrm{mT} \mathrm{N} 2$ on a $\mathrm{Si}(001)$ substrate at $\mathrm{Ed} \sim 0.66 \mathrm{~J} / \mathrm{cm}^{2}$ and $\mathrm{T}=320^{\circ} \mathrm{C}$ (see text). $\mathrm{R}=0$ is the common rotation axis passing through the center of the rotating heater face and the center of the rotating ablation target. The dashed straight lines are least squares fits to the data.

Figure 2. Hole concentration and mobility vs. nitrogen pressure for $\mathrm{p}-\mathrm{ZnTe}$ films grown at $\mathrm{T}=320^{\circ} \mathrm{C}$ using $E_{d}=0.66 \mathrm{~J} / \mathrm{cm}^{2}$.

Figure 3. Full width at half maximum (FWHM) peak width $\Delta \mathrm{Q}$ vs. $Q$ for the $(00 \ell)$ reflections of the $\mathrm{ZnTe}$ films whose properties and growth conditions are listed in Table I: (a) $\mathrm{Ed}_{\mathrm{d}}=0.66 \mathrm{~J} / \mathrm{cm}^{2}, 100$ mT N2; (b) $\mathrm{Ed}_{\mathrm{d}}=2.7 \mathrm{~J} / \mathrm{cm}^{2}, 100$ mT N2; (c) $\mathrm{E}_{\mathrm{d}}=2.7 \mathrm{~J} / \mathrm{cm}^{2}, 50 \mathrm{mT}$ Ar. The slopes of the plots reveal strain, their intercepts the particle size or coherence length. Inset: $\varnothing$-scan for the $\mathrm{ZnTe}(404)$ reflection for film (a), which has the highest hole concentration and mobility. 
However, recent theoretical calculations 27,28 suggest that $\mathrm{N}_{2}$ molecules in the metastable $\mathrm{A}^{3} \Sigma_{\mathrm{u}^{+}}{ }^{+}$state may be able to adsorb on a growing film surface and subsequently dissociate. Vaudo et al. ruled out this pathway as being unlikely using a thermal MBE-growth atomic flux. However, the kinetic energies of ablated atoms and ions are more than sufficient, over a wide range of $\mathrm{p}\left[\mathrm{N}_{2}\right]$ values, to supply the $3.9 \mathrm{eV}$ dissociation energy needed to break the molecular bond of the $\mathrm{A}^{3} \Sigma_{\mathrm{u}}{ }^{+}$state. A second possible N-doping mechanism in PLA growth is the direct kinetic energy-enhanced reaction of $\mathrm{Zn}$ atoms with $\mathrm{N}_{2}$ to form (possibly transient) $\mathrm{Zn}-\mathrm{N}$ compounds in the incoming ablation beam, and their subsequent incorporation in ZnTe:N films. Spectroscopic studies on and very near the growing film surface are needed to resolve these possibilities.

In summary, this appears to be the first time that any wide band gap $\left(E_{g}>2 \mathrm{eV}\right) \mathrm{II}-\mathrm{VI}$ compound (or other) semiconductor has been impurity-doped from the gas phase by laser ablation. In combination with the recent discovery that epitaxial $\mathrm{ZnSe}_{1-x} \mathrm{~S}_{x}$ films and heterostructures with continuously variable composition can be grown by ablation from a single target of fixed composition, 22 these results appear to open the way to explore PLA growth and doping of compound semiconductors as a possible alternative to molecular beam epitaxy.

This research was sponsored by the Division of Materials Science, U. S. Department of Energy, under contract no. DE-AC05-84OR21400 with Martin Marietta Energy Systems, Inc.

\section{REFERENCES}

1. R. M. Park et al., Appl. Phys. Lett. 57, 2127 (1990).

2. K. Ohkawa, T. Karasawa, and T. Mitsuyu, Jap. J. Appl. Phys. 30, L152 (1991).

3. M. Haase, J. Qiu, J. DePuydt, and H. Cheng, Appl. Phys. Lett. 59, 1272 (1991).

4. H. Jeon et al., Appl. Phys. Lett. 60, 2045 (1992).

5. J. Han et al., Appl. Phys. Lett. 62, 840 (1993).

6. Y. Fan et al., Appl. Phys. Lett. 61, 3160 (1992).

7. R. P. Vaudo, J. W. Cook, Jr., and J. F. Schetzina, J. Cryst. Growth 138, 430 (1994).

8. S. O. Ferreira et al., J. Cryst. Growth 140, 282 (1994).

9. T. Baron et al., Appl. Phys. Lett. 65, 1284 (1994).

10. W. P. Shen and H. S. Kwok, Fall 1993 Annual Mtg. of the Mater. Rres. Soc., Boston, MA (to be published, 1994).

11. A. Compaan et al., p. 957 in Proc. 22nd IEEE Photovoltaic Specialists Conf., IEEE, 1991.

12. A. Compaan and A. Bhat, Int. J. Solar Energy 12, 155 (1992).

13. J. J. Dubowski et al., Superlattices and Microstructures 9, 327 (1991).

14. D. Labrie and J. J. Dubowski, Mat. Res. Soc. Symp. Proc. 285, 465 (1993).

15. J. M. Wrobel and J. J. Dubowski, Appl. Phys. Lett. 55, 469 (1989).

16. J. J. Dubowski, J. Cryst. Growth 101, 105 (1990).

17. J. J. Dubowski, private communication.

18. R. L. Harper, Jr., et al., J. Appl. Phys. 65, 624 (1989).

19. D. H. Lowndes, "Growth of Epitaxial Thin Films by Pulsed Laser Ablation", in Modern Topics in Single Crystal Growth, Amer. Inst. of Physics (Eighth Int. Summer School on Crystal Growth, Palm Springs, CA, Aug. 9-15, 1992), in press.

20. The $99.999 \%$ pure ZnTe target was prepared by isostatic hot pressing at Plasmetrics, Inc., San Ramon, CA.

21. We find that the areal density of particulates on PLA compound semiconductor films is much lower than for oxide ceramics. By using the techniques that we and others have developed to minimize particulate production due to target "coning" and damage, nearly particulate-free compound semiconductor films can be obtained.

22. J. W. McCamy, D. H. Lowndes, and J. D. Budai, Appl. Phys. Lett. 63, 3008 (1993).

23. D. B. Geohegan, p. 115 in Pulsed Laser Deposition of Thin Films, ed. by D. B. Chrisey and G. K. Hubler, Wiley, New York, 1994.

24. E. Abramof et al., Semicond. Sci. and Technol. 6, A80 (1991).

25. D. B. Geohegan et al., these symposium proceedings.

26. C. M. Rouleau and D. H. Lowndes, unpublished results.

27. T. Nakao and T. Uenoyama, Jpn. J. Appl. Phys. 32, 660 (1993).

28. T. Uenoyama, T. Nakao, and M. Suzuki, J. Cryst. Growth 138, 301 (1994). 